\title{
Myanmar: viento de democracia, viento de dictadura. Una mirada desde el mundo de la novela gráfica
}

\author{
Antonio César Moreno Cantano \\ Universidad Complutense de Madrid (España) \\ https://orcid.org/0000-0003-1008-2831
}

\author{
FERNANDO NUÑo SANTANA \\ Universitat Oberta de Catalunya (España) \\ https://orcid.org/0000-0002-9625-0439
}

Presentación: 14 jun. 2021 | Aceptación: 23 oct. 2021 | Publicación: 15 dic. 2021

Cita recomendada: Moreno Cantano, Antonio César, y Fernando Nuño Santana. 2021. «Myanmar: viento de democracia, viento de dictadura. Una mirada desde el mundo de la novela gráfica». Dictatorships \& Democracies. Journal of History and Culture 9: 141-153. doi: https://dx.doi.org/10.7238/ dd.voig.393242

Resumen: La imagen, a diferencia del texto, presenta un componente afectivo que permite al observador empatizar, implicarse, con aquello que ve. Uno de los sucesos que más ha llamado la atención de la comunidad internacional en la actualidad ha sido la crisis de los rohingyas, minoría étnica musulmana intensamente perseguida en Myanmar, cuya violencia ha forzado uno de los mayores exilios del siglo xxi. A lo largo del presente artículo, y tras un marco teórico sobre la conexión entre problemas actuales y novelas gráficas, analizaremos cómo a través de este formato se ha representado la convulsa situación política del país. Nuestra atención se centra en títulos como Crónicas birmanas, Myanmar's Rohingya Refugees o Aung San Suu Kyi. La Dame de Rangoon. Como conclusión, destacamos la validez de este género para aproximar de una manera documentada la complejidad de esta crisis y la diversidad de actores e intereses implicados.

Palabras clave: Myanmar, rohingyas, novelas gráficas, crisis humanitaria, empatía

\section{Myanmar: Wind of Democracy, Wind of Dictatorship. A Look from the Perspective of Graphic Novels}

Abstract: Images, unlike words, have an affective component that allows the observer to empathise, to become involved, with what he or she is seeing. One of the events that has lately attracted more attention of the international community has been the Rohingya crisis in Myanmar. The violence against this intensely persecuted Muslim ethnic minority has led to one of the largest exiles of the 21st century. Throughout this article, and after establishing a theoretical framework on the connection between current issues and graphic novels, we will analyse how the convulsive political situation of the country 
has been represented through this format. We will focus our attention on titles such as Burma Chronicles, Myanmar's Rohingya Refugees or Aung San Suu Kyi. La Dame de Rangoon. In closing, we will highlight the validity of this genre to provide a documented approach of the complexity of this crisis and the diversity of actors and interests involved. Keywords: Myanmar, Rohingyas, graphic novels, humanitarian crisis, empathy

\section{Problemas actuales y novelas gráficas: marco teórico e historiográfico}

El uso del dibujo como representación y testimonio documental de los grandes conflictos tiene una larga tradición. En el caso español, uno de los ejemplos más paradigmáticos lo constituye la serie de grabados de Francisco Goya conocida como Los desastres de la guerra, centrados en la Guerra de Independencia. Previamente, y retrotrayéndonos al siglo XVII, podemos también nombrar Les grandes misères de la guerre (1633), de Jacques Callot, que reflejaban la dureza y violencia de la Guerra de los Treinta Años (Pérez 2020). Estos ejemplos primigenios evidencian la relevancia de la imagen como fuente primaria, como documento histórico, tal y como han reivindicado, entre otros, los historiadores Francis Haskell (1994), Michael A. Holly(1996) o Peter Burke (2001).

Desde el campo de la ciencia política, y en especial el de las relaciones internacionales, en los últimos años se ha asistido a un giro cultural y estético en el que se reclama validar todo el registro de percepciones y sensaciones humanas, no solo las prácticas de la razón y el logos que prevalecen en los estudios convencionales. Así, se pretende tener en cuenta otras formas de percepción más creativas y abiertas pero igualmente importantes, «cultivar una actitud crítica respecto a cómo entendemos y nos comprometemos con el mundo político que nos rodea» (Bleiker 2001). Como enfatiza el teórico de estudios culturales, Michael J. Shapiro (2013, 16 y 143), se busca «conocer las vinculaciones que se establecen con el mundo al que pertenecemos». Para ello, este grupo heterogéneo de investigadores no duda en incorporar planteamientos filosóficos o psicológicos a los estudios de la representación de la realidad: «Nuestra visión de las cosas está determinada por la mirada que le otorgamos»; es decir, va más allá de una percepción física y está determinada por el contexto cultural, político y social del receptor. Hay una relación cada 
vez más creciente e intensa entre geopolítica y cultura visual, en la que la afectividad, las emociones y el recuerdo adquieren cada vez un mayor peso (Carter \& McCormack 2010). Es imposible entender una imagen, una representación, un dibujo, de manera aislada, sin tener en consideración el contexto social, cultural y político en los que se producen y la manera en el que este medio determina lo reflejado en sus páginas, en las finas hojas de papel de un cómic, de un lienzo (McAllister, Sewell \& Gordon 2009). ¿Acaso son entendibles los trazos de Delisle en Crónicas birmanas si no conocemos el pasado colonial de este país? ¿Podemos empatizar plenamente con los diálogos que crea Thurman en su obra estando afectivamente alejados de la persecución política y social que sufre la minoría musulmana de los rohingya?

La importancia de las novelas gráficas, de esta mixtura cultural entre texto e imagen, para el estudio de la realidad internacional tiene en la investigadora danesa Lene Hansen a uno de sus principales baluartes. En uno de sus ensayos más recientes, de 2017, destacaba cuatro razones por las que los cómics debían incorporarse al análisis de las relaciones internacionales: $a$ ) son una forma relevante de la cultura popular; $b$ ) pueden servir para dar salida a discursos críticos y marginales; $c$ ) su contenido y sus creadores son sociológicamente significativos para la mediación y la experiencia de la política exterior, y $d$ ) pueden abordar e impulsar investigaciones importantes para las relaciones internacionales. Pese a que hasta el año 2016 se contabilizaban pocos artículos relacionados con las relaciones internacionales y los cómics, en los que además se incidía casi en exclusiva en su potencial pedagógico como recurso didáctico - por ejemplo, Juneau \& Sucharov 2010 y Sola \& Barroso 2014-, la tendencia ha cambiado notablemente en los últimos tiempos. Además del susodicho texto de Hansen, y sin ánimo de ser exhaustivos, podemos nombrar el ensayo previo de Jeff Adams, Documentary Graphic Novels and Social Realism (2008), o las obra colectivas Comics and Power (2015) y Cultures of War in Graphic Novels (2018). También se deben tener en cuenta los artículos aparecidos en la revista CuCo. Cuadernos de Cómics, resaltando el de Muñoz (2017) y, en especial, el de David Fernández de Arriba, «Las relaciones internacionales en la novela gráfica» (2016), todo un catálogo de cómo este formato cubre una amplia totalidad de 
conflictos actuales y pasados, desde el genocidio de Ruanda hasta las tensiones en Oriente Medio.

El presente ensayo quiere continuar esta senda y pretende analizar y mostrar al lector y al académico las principales novelas gráficas que se han ocupado de Myanmar. En especial, aquellas que han analizado con cierta profundidad los acontecimientos más recientes, esperanzadores y trágicos del país, ligados a los procesos de democratización y autoritarismo. Dos temas han marcado profundamente la realidad birmana en la última década: la situación de los rohingyas, minoría étnica musulmana de Myanmar, considerados apátridas desde la ley birmana de ciudadanía de 1982 y fuertemente perseguidos por razones históricas, culturales, religiosas y económicas, en especial en las últimas décadas, y la evolución política de la líder birmana Aung San Suu Kyi, quien guio el difícil proceso democrático en el país tras más de medio siglo de dictadura militar. Abordar la complejidad de ambas materias es imposible en estas pocas líneas, y por ello apuntaremos como complemento únicamente algunos ensayos y documentales que tratan de manera más exhaustiva y determinada estos asuntos. La persecución de los rohingyas, que en algunos medios se ha catalogado como una «limpieza étnica de manual», ha sido analizada magistralmente en el libro de Ronan Lee Myanmar's Rohingya Genocide (2020), en el del periodista español Carlos Sardiña, The Burmese Labyrinth (2020), o en los ensayos de 2005 y de 2007 de la internacionalista Mary P. Callahan, entre otros. Para comprender las raíces del odio hacia los rohingyas y sus connotaciones culturales y religiosas, en el campo audiovisual sobresale El venerable $W$, del director francosuizo Barbet Schroeder. En él desmonta los argumentos del líder budista ultranacionalista y antiislamista Ashin Wirathu, máximo responsable del movimiento 969 (en la actualidad Ma Ba Tha), que llama a la eliminación de los rohingyas, a los que considera extranjeros y terroristas. Muchas de estas cuestiones estarán presentes en las novelas gráficas escogidas y sirven para poner en contexto el controvertido papel de la Premio Nobel Aung San Suu Kyi, que ha priorizado el nacionalismo al derecho a la identidad de esta etnia (Karim 2020). 


\section{De Aventure birmane a Den gyllene triangeln}

En el siglo Xxi, ha habido una cantidad relevante de tebeos y novelas gráficas sobre Myanmar que han contribuido a la difusión popular de este país, menos conocido por la opinión pública occidental que otros de sus vecinos de la península indochina, como Tailandia o Vietnam. Antes de 1988, Myanmar (cuyo nombre anterior era Birmania) no ocupaba un lugar destacado en las historietas, los cómics y las novelas gráficas, pero, tras el levantamiento nacional de ese año en favor de la democracia, la situación cambió. Con el apoyo de una campaña internacional contra el régimen militar, Myanmar encontró un nuevo lugar en la cultura popular. Desde entonces, este país ha aparecido en más de una veintena de cómics (Selth 2018).

Las primeras novelas gráficas sobre Birmania consistieron en recopilaciones de tiras que habían aparecido en diferentes periódicos americanos, europeos y asiáticos. Esta práctica resultó habitual en el periodo que va de 1930 a 1950 e incluyó, entre otros, los trabajos en blanco y negro de Leo O’Mealia sobre el villano mandarín Fu Manchú. En el El escorpión de oro (1929) y El demonio amarillo (originalmente The Mystery of Dr. Fu-Man$c h u, 1935)$, el perverso doctor antioccidental desarrolla sus proyectos en escenarios birmanos como Yangón, Mawlamyaing, Pyay o el río Irawadi.

Sin embargo, fue la Segunda Guerra Mundial y la campaña militar aliada contra la invasión del Ejército japonés la que proporcionó una importante visibilidad a los cómics y novelas gráficas que se desarrollaban en suelo birmano. Entre ellas, al álbum francés Les tigres volants, de Nolane y Molinari, o a la británica Darkie’s Mob, de John Wagner y Michael Western, publicada originalmente en la década de 1970. En ambas series y en otras posteriores, los autores explotan la imagen exótica de Myanmar como país aislado, de bosques tropicales, exuberantes pagodas y peligros que acechan en cualquier esquina. La Birmania rural es la elegida como escenario principal en este periodo anterior a 1988. Es un ciclo donde los contenidos editoriales empiezan a diversificar la descripción del mosaico birmano: los autores parecen interesarse cada vez más por reflejar de manera más detallada algunas diferencias entre las minorías del país.

Myanmar, al igual que ocurre con Tailandia y Laos, no ha escapado de los lugares comunes asociados a formar parte del denominado Triángulo 
de Oro. A juzgar por el contenido de numerosas historietas de la época, el país parece un escenario ideal para encuentros románticos interraciales donde se cruzan traficantes de opio, espías, guerrilleros, autoridades corruptas y extranjeros perdidos. La producción es variada en los años setenta y ochenta, incluyendo la serie francesa de 1976 Aventure birmane. Otro exponente parecido en el mundo de la edición es el de una novela gráfica sueca de 1983 sobre James Bond, titulada precisamente Den gyllene triangeln ('El Triángulo de Oro'), dibujada por Escolano y escrita por los noruegos Terje Nordberg y Eirik Ildahl (Selth 2018).

A partir de 1988, los temas de los cómics inspirados en Myanmar se nutren con componentes nuevos, no siempre centrados en los habituales enfoques bélicos, políticos y sociales. Hablan de otras realidades muy presentes en la región, como el tráfico de drogas o el turismo sexual. Algunos trabajos contienen elementos chamánicos, comola serie Mandalay. Por su parte, la colección Hot nights in Rangoon (1989), de J. H. Hauper (1989), recoge historias sobre mafia, espionaje y sexo. Con escenas en Yangón y Mandalay, la obra es una sucesión de encuentros sexuales de sus protagonistas con el mismo nivel de detalle que de descuido en el trabajo de documentación sobre el país.

\section{De Crónicas birmanas a Aung San Suu Kyi. La Dame de Rangoon}

La revolución democratizadora que se produjo en el país durante 2007 - bautizada como la Revolución del Azafrán por la participación de monjes budistas - y el paso del ciclón Nargis por el territorio en mayo de 2008, ocasionando demoledores estragos, acrecentaron el interés de la opinión pública internacional por Myanmar. Estos dos eventos propiciaron también periodos de discusión pública y política en los que se planteaba la eventual necesidad de una intervención internacional en los asuntos internos del país. Ambos generaron numerosas columnas y debates en medios de comunicación. Además, estimularon la aparición de novelas gráficas de calidad sobre Myanmar, obras que, a su vez, promovieron el surgimiento de una esfera pública transnacional donde se debatía a escala mundial sobre cuestiones universales que afectaban los derechos sociales fundamentales (Brooten 2008). 
Es en ese periodo cuando surgen algunos de los volúmenes más valiosos para analizar los múltiples prismas de la complejidad birmana desde la mirada de la novela gráfica. Crónicas birmanas (2007), de Guy Delisle, de la que se ha agotado ya su sexta edición, es una de las novelas gráficas que más ha contribuido a difundir el conocimiento de Myanmar, especialmente en los países occidentales. La de Delisle no es ni una narración épica ni una obra de denuncia directa; es un testimonio que huye de los lugares comunes y los mensajes simplificadores para alcanzar una aproximación íntima a la realidad cotidiana de los birmanos y a la omnipresencia del Tatmadaw (las Fuerzas Armadas birmanas) en los últimos sesenta años.

El autor quebequés publicó anteriormente Pyongyang (2005) y Shenzhen (2006). Ambas describen las vivencias de Delisle primeramente como director de animación en la capital norcoreana y, posteriormente, en la ciudad china que fue elegida por Deng Xiaoping como laboratorio de la llamada "economía socialista de mercado" y que pasó de tener 30.000 habitantes en 1980 a más de 10 millones en la actualidad. Sin embargo, Crónicas birmanas va más allá de la experiencia personal del autor y analiza la complejidad del caso birmano y sus numerosas aristas, añadiendo a la narración gráfica un notable trabajo de recopilación de fuentes primarias y secundarias que contribuyen a entender la evolución reciente de Myanmar desde un enfoque distinto a otros estudios sobre el país. Esta obra ha sido traducida a diecisiete idiomas, entre ellos el chino, lo que ha contribuido al conocimiento popular de diversos aspectos de Birmania y de su compleja evolución política en los años previos a la apertura democrática.

Más recientemente, la pérdida del difícil equilibrio entre las diferentes piezas del mosaico étnico de Myanmar, con 132 minorías reconocidas (Thurman 2016), que ha conllevado la brutal represión de los rohingya (2010-2020), junto con el golpe de Estado de 2021, que ha apartado del poder a la líder Aung San Suu Kyi, han vuelto a despertar el interés internacional por Myanmar. En relación con la situación del país, el universo creativo y narrativo de la novela gráfica ha convertido en uno de sus temas centrales de análisis el ascenso de Aung San Suu Kyi como icono de la democracia, de la vía pacífica de resolución de conflictos y de los valores humanos. La Dama, como es conocida en el país, recibió el Nobel de la Paz en 1991 por 

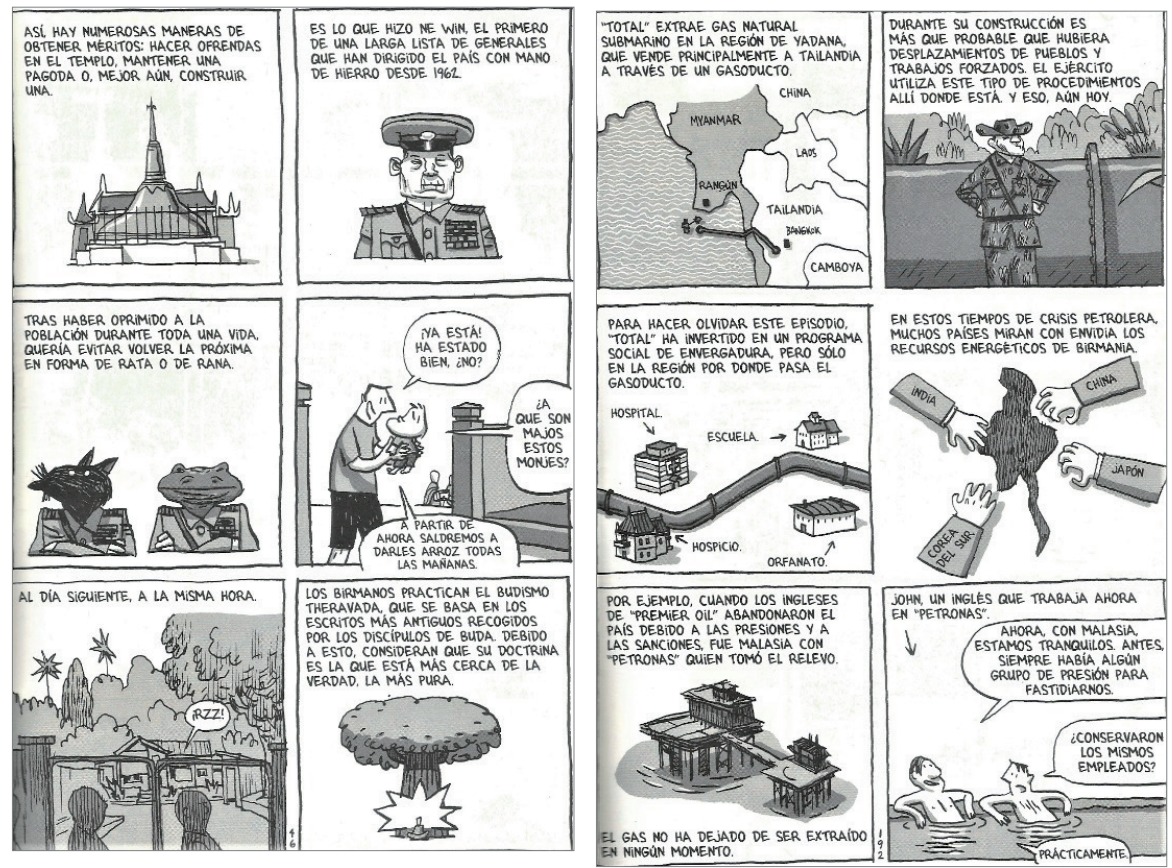

1 Página 46 y 192 de Crónicas birmanas (Astiberri, 2016).

ser, en palabras de la Academia Sueca, «un ejemplo extraordinario del poder de los que no tienen poder».

En 2008, el autor Bernard Cosey dedica a Myanmar un volumen de su popular serie Jonathan, plasmando un viaje personal por el norte del país en busca de la iluminación en Ella o diez mil luciérnagas. Otros novelistas gráficos, como el propio Delisle, harán menciones en su obra a las incursiones personales en la meditación y el budismo theravada.

En este segundo periodo de análisis (2007-2021) encontramos numerosos volúmenes que tienen a Aung San Suu Kyi como protagonista. Es el caso de Aung San Suu Kyi. La Dame de Rangoon (2013), de Chantal van den Heuvel y Michel Pierret, y Myanmar's Rohingya Refugees (2016), de Erik Thurman, el primero en edición impresa y el segundo en línea y de consulta libre. El cómic de Thurman ha sido publicado en The Nib, un diario de historietas digital que forma parte de First Look Media, una organización de medios independientes de los Estados Unidos. The Nib es un ejemplo 
evolutivo de cómo las novelas gráficas se han convertido en una fuente de datos útiles en el análisis visual de los fenómenos políticos nacionales y mundiales, debido a la capacidad del medio para evocar emociones y significados universales más allá de las fronteras nacionales y al margen de las limitaciones lingüísticas (Sani et al. 2012, 156-164).

Tanto la obra de Van den Heuvel y Pierret como la de Thurman enfrentan la imagen heroica de Aung San Suu Kyi a sus controvertidos silencios ante la crisis de los refugiados y ante los abusos del Ejército birmano, que, según alertaba el Informe Rosenthal (encargado por el secretario general de Naciones Unidas, António Guterres), infringió en 2017 «graves violaciones de los derechos humanos» en relación con los refugiados rohingyas.

La líder de la oposición al régimen militar representa el tema central de la novela gráfica de Van den Heuvel y Pierret. Aung San Suu Kyi. La Dame de Rangoon repasa la vida personal de Aung San Suu Kyi desde su época estudiantil en Londres y su matrimonio con el británico Michael Aris hasta que se convierte en madre y se enfrenta al dilema de dejar a su familia para luchar por la democracia en su país.

Los cómics de Delisle y Thurman contribuyen al estudio de la situación política birmana, de las relaciones internacionales del país y del papel de los medios de comunicación partiendo de un relevante trabajo de documentación previo. Representan acontecimientos traumáticos y traducen investigaciones complejas a través de un lenguaje de imágenes secuenciales. En este sentido, son ilustrativos la emergencia de nuevos géneros como el cómic periodístico o el uso de novelas gráficas en la enseñanza académica de las relaciones internacionales (Juneau \& Sucharov 2010; Cascante et al. 2021).

Crónicas birmanas y Myanmar's Rohingya Refugees reflejan — de forma sutil en el primer caso y de forma explícita en el segundo- las presiones de las organizaciones internacionales y los grupos de la sociedad civil nacionales e internacionales que han trabajado desde dentro del territorio birmano. Tanto Delisle como Thurman hacen referencia, entre otras ONG, a Médicos Sin Fronteras (MSF) y a las dificultades que se encuentran para cumplir su misión humanitaria. El trabajo de la mujer de Delisle para MSF en Myanmar fue la razón que lo llevó a trasladarse al país en familia e iniciar su proyecto de Crónicas birmanas. 

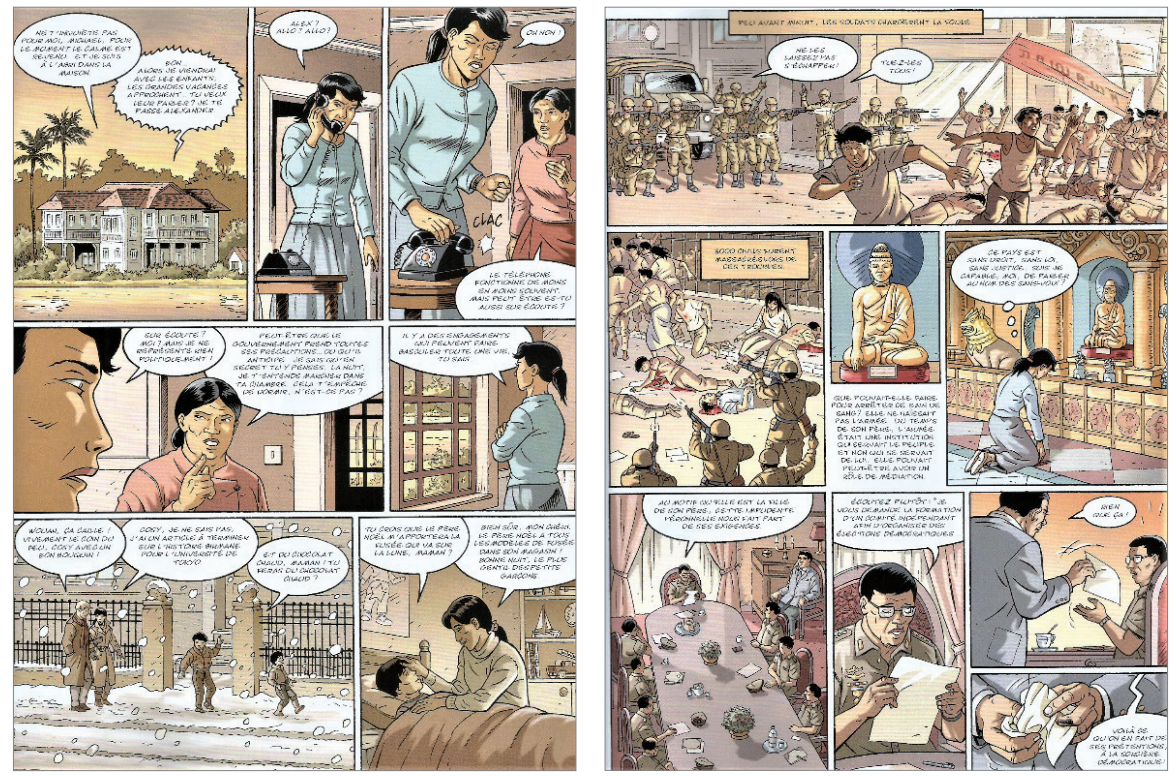

2 Página 15 y 21 de Aung San Suu Kyi. La Dame de Rangoon (Coccinelle Éditions, 2013).

Tanto el volumen de Delisle (272 páginas) como los de Pierret y Van den Heuvel (52 páginas) y de Thurman (17 páginas) cuentan con una notable preparación documental, pese a la gran diferencia de longitud entre ellas. Solo así es posible que Crónicas birmanas trate la censura informativa, la deficiente atención sanitaria en las zonas rurales del país, el negocio petrolero, la disidencia, la relación entre el poder y el Ejército, la cultura birmana, el budismo e, incluso, la cotidianidad de padre primerizo del mismo Delisle en un solo volumen.

Algunas de las creativas fuentes de información alternativas que han acompañado al llamamiento de la comunidad internacional a abordar la crisis de los rohingyas en los últimos años han llegado de imágenes y materiales de reporteros gráficos, caricaturistas y cineastas que han documentado el sufrimiento cotidiano de los refugiados. Asimismo, estos mismos actores han impulsado que varios países de la región reconozcan la «responsabilidad de proteger» a los refugiados rohingyas (Kneebone 2016).

Por otro lado, la representación de la tragedia de estos refugiados a través de las obras de Pierret, Van den Heuvel y Thurman pone sobre la 
mesa las contradicciones de la líder birmana Aung San Suu Kyi, que no ha hecho ningún tipo de autocrítica pública ni ha reconocido la existencia de las campañas del Ejército birmano que han culminado en la huida desesperada de cientos de miles de rohingyas en el último decenio.

\section{Conclusiones}

Desdeñada durante mucho tiempo en los análisis de la realidad internacional, la imagen, la representación de todo aquello que nos rodea, ya sea a través de las instantáneas del fotoperiodista, los trazos del cronista o los carboncillos del dibujante, está adquiriendo en la actualidad una gran relevancia. Las imágenes despiertan la empatía, la afectividad, es decir, dan visibilidad emotiva a aquellos acontecimientos que - en la mayoría de los casos - son lejanos para el ciudadano de a pie. Los títulos seleccionados tienen como público objetivo el mundo occidental, que en muchas ocasiones tiene un conocimiento muy sesgado y escaso de problemáticas como las de los rohingyas. En este sentido, las novelas gráficas analizadas pueden constituir una primera aproximación documentada, a la par que divulgativa, sobre esta trágica realidad a través del poder de atracción y estimulador de la imagen, de la viñeta. De manera creciente, los lectores acuden a este medio para llegar a conocer la verdad de estos sucesos mundiales particulares. Consumen historias dramáticas ligadas a la realidad, ya sean sobre el genocidio ruandés (Deogratias, 2000, de J. P. Stassen), la Primavera Árabe (Freedom Hospital, 2017, de Hamid Sulaiman), la vida en un país sin libertades (Pyongyang, 2004, del susodicho Guy Delisle) o la persecución y exclusión políticosocial en su propia nación (tal y como hemos señalado en estas páginas) de manera accesible y con un lenguaje aparentemente sencillo pero de una intensa carga emocional. Bajo esta maniobra artístico-comunicativa, los escritores-ilustradores pueden hacer llegar sus historias (muchas de ellas vivencias propias y memorísticas) de una manera más directa y potente que mediante cualquier informe o ensayo académico.

Queda por ver cómo evoluciona Myanmar tras la reclusión forzada de Aung San Suu Kyi, con el regreso de la omnipresencia militar y la brutal represión tras el golpe de Estado de 2021, que deja nuevamente en el 
aire el anhelo democrático y de paz en Myanmar. El territorio birmano experimenta de forma cíclica vientos de democracia y de dictadura. Y esa noria que muestra la última viñeta de Crónicas birmanas refleja, en una metáfora visual, un ciclo democrático que nunca termina de cerrarse.

\section{Bibliografía}

Adams, Jeff. 2008. Documentary Graphic Novels and Social Realism. Nueva York: Peter Lang. Karim, Mohd. 2020. Genocide and Geopolitics of the Rohingya Crisis. Nueva York: Nova Science Publishers.

Bleiker, Roland. 2001. «The Aesthetic Turn in International Political Theory». Millennium: Journal of International Studies 30 (3): 509-533. https://journals. sagepub.com/doi/10.1177/03058298010300031001.

Brooten, Lisa. 2008. «Burmese Political Cartoons and the Transnational Public Sphere in Times of Crisis». International Journal of Comic Art 10 (2): 253-281.

Burke, Peter. 2001. Eyewitnessing. The Uses of Images as Historical Evidence. Nueva York: Cornell University Press.

Callahan, Mary P. 2005. Political Authority in Burma's Ethnic Minority States. Devolution, Occupation, and Coexistence. Singapur: East-West Center.

- 2007. Marking Enemies: War and State Building in Burma. Nueva York: Cornell University Press.

Carter, Sean y Derek McCormarck. 2010. «Affectivity and Geopolitical Images». Dentro Fraser MacDonald, Rachel Hughes y Klaus Dodds, ed., Observant States. Geopolitics and Visual Culture. Londres: I. B. Tauris, 319-323.

Cascante, Kattya, Raquel Barras, Elisa Bravo, Ana María Martínez, Antonio César Moreno, Fernando Eutiquio Nuño y Xira del Pilar Ruiz. 2021. Guía de metodologías activas para el aprendizaje de relaciones internacionales y desarrollo de nuevas competencias. Universidad Complutense de Madrid. https://eprints.ucm.es/id/ eprint $/ 65832 /$.

Debomy, Frédéric, y Benoît Guillaume. 2020. Aung San Suu Kyi, Rohingya et extrémistes bouddhistes. París: Massot Éditions.

Delisle, Guy. 2007. Chroniques birmanes. París: Guy Delcourt Productions.

Fernández de Arriba, David. 2016. «Las relaciones internacionales en la novela gráfica. Una aproximación». CuCo. Cuadernos de Cómics 6: 62-79. https://erevistas. publicaciones.uah.es/ojs/index.php/cuadernosdecomic/article/view/1151/664.

Hansen, Lene. 2017. «Reading Comics for the Field of International Relations: Theory, Method and the Bosnian War». European Journal of International Relations 23 (3): 581-6o8. https://journals.sagepub.com/doi/10.1177/1354066116656763.

Haskell, Francis. 1994. La historia y sus imágenes. El arte y la interpretación del pasado. Madrid: Alianza. 
Holly, Michael A. 1996. Past Looking: Historical Imagination and the Rhetoric of the Image. Nueva York: Cornell University Press.

Juneau, Thomas, y Mira Sucharov. 2010. «Narratives in Pencil: Using Graphic Novels to Teach Israeli-Palestinian Relations». International Studies Perspectives 11 (2): 172-183. https://www.jstor.org/stable/44218631.

Lee, Ronan. 2020. Myanmar's Rohingya Genocide. Identity, History and Hate Speech. Londres: I.B. Tauris.

Lent, John A. 2014. Southeast Asian Cartoon Art: History, Trends and Problems. Carolina del Norte: McFarland.

Magnussen, Anne, Erin la Cour y Rikke Platz, ed. 2015. Comics and Power: Representing and Questioning Culture, Subjects and Communities. Cambridge: Cambridge Scholars Publishing.

McAllister, Matthew, Edward H. Sewell y Ian Gordon, ed. 2009. Comics and Ideology. Berna: Peter Lang.

Muñoz, Edward L. 2017. «El cómic como lenguaje visual híbrido y su vigencia en la era digital contemporánea». CuCo. Cuadernos de Cómics 8: 7-30. http:// cuadernosdecomic.com/docs/revista8/El_comic_como_lenguaje_visual_ hibrido_y_su_vigencia_en_la_era_digital_comtemporanea.pdf.

Pérez, Juan C. 2020. «La memoria traumática sobre la Guerra Civil española en el cómic». Dentro Viviane Alary y Michel Matly, ed., Narrativa gráfica de la Guerra Civil. Perspectivas globales y particulares, 247-264. León: Eolas Ediciones.

Pierret, Michel, y Chantal van den Heuvel. 2013. Aung San Suu Kyi. La Dame de Rangoon. Bruselas: Coccinelle Éditions.

Prorokova, Tatiana, y Nimrod Tal. 2018. Cultures of War in Graphic Novels: Violence, Trauma and Memory. Nueva Jersey: Rutgers University Press.

Sani, Iro, Mardziah Hayati Abdullah, Faiz Sathi Abdullah y Afida Mohamad Ali. 2012. «Political Cartoons as a Vehicle of Setting Social Agenda: The Newspaper Example». Asian Social Science 8 (6): 156-164.

Sardiña, Carlos. 2020. The Burmese Labyrinth. A History of the Rohingya Tragedy. Londres: Verso Books.

Schroeder, Barbet. 2017. Le vénérable W. París: Les Films du Losange.

Shapiro, Michael. 2013. Studies in Trans-Disciplinary Method. Londres: Routledge.

Selth, Andrew. 2018. «Graphic Novels Chart Myanmar's History».

Nikkei Asia, 1 abr. https://asia.nikkei.com/Life-Arts/Arts/

Graphic-novels-chart-Myanmar-s-history?page=1.

Thurman, Erik. 2016. Myanmar's Rohingya Refugees. Portland: The Nib, 1 ag. https:// thenib.com/myanmar-s-rohingya-refugees/.

Vandensteen Manaysay, Ferth. 2019. «Illustrating Political Discourse: Comics and the Rohingya Refugee Crisis». Yogyakarta: The Indonesian Journal of Southeast Asian Studies 3 (1): 45-74. 
